\title{
Differential subcellular and extracellular localisations of proteins required for insulin-like growth factor- and extracellular matrix-induced signalling events in breast cancer progression
}

Helen C Plant ${ }^{1 \dagger}$, Abhishek S Kashyap ${ }^{1 * \dagger}$, Kerry J Manton ${ }^{1}$, Brett G Hollier ${ }^{1}$, Cameron P Hurst ${ }^{2}$, Sandra R Stein ${ }^{3}$, Glenn D Francis ${ }^{3}$, Geoffrey F Beadle ${ }^{4}$, Zee Upton ${ }^{1}$ and David I Leavesley ${ }^{1}$

\begin{abstract}
Background: Cancer metastasis is the main contributor to breast cancer fatalities as women with the metastatic disease have poorer survival outcomes than women with localised breast cancers. There is an urgent need to develop appropriate prognostic methods to stratify patients based on the propensities of their cancers to metastasise. The insulin-like growth factor (IGF)-I: IGF binding protein (IGFBP):vitronectin complexes have been shown to stimulate changes in gene expression favouring increased breast cancer cell survival and a migratory phenotype. We therefore investigated the prognostic potential of these IGF- and extracellular matrix (ECM) interaction-induced proteins in the early identification of breast cancers with a propensity to metastasise using patient-derived tissue microarrays.

Methods: Semiquantitative immunohistochemistry analyses were performed to compare the extracellular and subcellular distribution of IGF- and ECM-induced signalling proteins among matched normal, primary cancer and metastatic cancer formalin-fixed paraffin-embedded breast tissue samples.

Results: The IGF- and ECM-induced signalling proteins were differentially expressed between subcellular and extracellular localisations. Vitronectin and IGFBP-5 immunoreactivity was lower while $\beta_{1}$ integrin immunoreactivity was higher in the stroma surrounding metastatic cancer tissues, as compared to normal breast and primary cancer stromal tissues. Similarly, immunoreactive stratifin was found to be increased in the stroma of primary as well as metastatic breast tissues. Immunoreactive fibronectin and $\beta_{1}$ integrin was found to be highly expressed at the leading edge of tumours. Based on the immunoreactivity it was apparent that the cell signalling proteins AKT1 and ERK1/2 shuffled from the nucleus to the cytoplasm with tumour progression.

Conclusion: This is the first in-depth, compartmentalised analysis of the distribution of IGF- and ECM-induced signalling proteins in metastatic breast cancers. This study has provided insights into the changing pattern of cellular localisation and expression of IGF- and ECM-induced signalling proteins in different stages of breast cancer. The differential distribution of these biomarkers could provide important prognostic and predictive indicators that may assist the clinical management of breast disease, namely in the early identification of cancers with a propensity to metastasise, and/or recur following adjuvant therapy.
\end{abstract}

Keywords: Biomarker, Breast cancer, Extracellular matrix, Insulin-like growth factor, Metastasis, Vitronectin

\footnotetext{
* Correspondence: a.kashyap@qut.edu.au

${ }^{\dagger}$ Equal contributors

'Tissue Repair and Regeneration Program, Institute of Health and Biomedical Innovation, Queensland University of Technology, Brisbane, Australia

Full list of author information is available at the end of the article
} 


\section{Background}

Experimental and clinical evidence has implicated a role for the insulin-like growth factor (IGF) axis in cancer progression [1]. In fact a number of inhibitors of, and antibodies directed against, the IGF type I receptor (IGF-IR) have been reported to show anti-tumour activity in vitro and in vivo, and are currently in clinical trials [2]. These studies, combined with many others, have highlighted the complexity of the dysregulation of the IGF system in cancers. Simply targeting the IGF-IR or the IGF system in isolation may therefore not be the most efficacious strategy for treating this disease; more complex therapeutic approaches to target the IGF system and prevent tumorigenesis and, in particular, metastasis, are likely to be required.

Cancer metastasis is the main contributor to breast cancer fatalities [3]. Women with metastatic breast cancers have considerably poorer survival outcomes than women whose cancers are localised to the breast $[4,5]$. Adjuvant systemic therapies for patients with breast cancer metastasis remain palliative [3]. Understanding the processes underpinning the progression of breast cancer, identifying patients likely to develop metastases and developing strategies to prevent the secondary spread of cancers are of significant clinical and financial relevance. There has also been a growing urgency to create costeffective and appropriate prognostic methods that can accurately resolve those patients with a poor prognosis that require more intense treatment regimes. The prognostic methods currently available are unable to adequately address this issue $[6,7]$.

A critical component that is often overlooked during the identification and analysis of prognostic biomarkers, and one which may explain the inability to develop adequate prognostic techniques thus far, is the interplay between tumour cells, the surrounding microenvironment and the growth factors present in this milieu. Cellular attachment and interactions with the extracellular matrix $(\mathrm{ECM})$ regulate biological responses vital for tumour progression. Considerable evidence indicates that interactions between proteins required for IGFinduced signalling events and those within the ECM contribute to processes leading to cancer progression. Studies by Kricker et al. [8] found that IGF-I stimulates migration of MCF-7 breast cancer cells when bound to the ECM protein vitronectin ( $\mathrm{VN}$ ) indirectly through the presence of IGF binding proteins (IGFBPs). The presence of function blocking antibodies against IGF-IR and VN-binding integrins abolished the enhanced migration of these cells [9], while, the overexpression of total-akt/ protein kinase $\mathrm{B}(\mathrm{AKT})$ and phosphorylated-akt/protein kinase B (P-AKT) enhanced IGF-I: IGFBP:VN-stimulated migration [9]. Gene microarray technology has also been applied to elucidate the molecular mechanisms involved in IGF-I: IGFBP:VN-stimulated migration of breast cancer cells in in vitro cell based assays [10]. These studies have identified a number of genes, including Stratifin (SFN), enhancer-of-split and hairy-related protein 2 (Sharp-2), Tissue Factor, Claudin-1 (CLDN1), that are uniquely regulated by the IGF-I: IGFBP:VN complex. The genes are known for their roles in migration, invasion as well as cell survival. However, to date the effects of IGF and ECM protein interactions on the dissemination and progression of breast cancer in vivo are unclear. Given this, we chose to investigate the clinical relevance of proteins required for IGF-induced signalling events and those within the ECM for the development and progression of breast cancer, as well as investigate these proteins as potential prognostic biomarkers.

\section{Methods}

\section{Human ethics approval}

Ethical approval for this work was obtained from the Queensland University of Technology, Australia (08000 00565), the Princess Alexandra Hospital Australia (2005/ 163), Royal Brisbane \& Women's Hospital, Australia (PR07/004) and Queensland Institute of Medical Research, Australia (P716). This project utilised archived human tissue samples collected between January 1970 and June 2005. The human tissue samples and patients records were collected as a routine part of clinical management of the breast disease. Patient consent was not required. All patient clinical information was obtained from the Queensland Cancer Registery (Australia) in a de-identified and encoded manner. Approval to use these samples and data was sought from Dr Glenn Francis and Queensland Health (Australia).

\section{Selection of patient specimen}

This project utilised formalin-fixed paraffin-embedded (FFPE) archival breast carcinoma specimens from 91 women who presented with metastatic breast carcinoma (refer to Additional file 1 and Additional file 2 for further details). These specimens were surgically removed from the breast and axillary lymph nodes (LNs). For each patient, tissues containing normal breast epithelial ducts, primary breast carcinoma and $\mathrm{LN}$ metastasis were identified from haematoxylin and eosin stained sections. Cores containing DCIS tissues were omitted due to low samples numbers. Details on the selected patient cohort are provided in Additional file 3 and Additional file 4.

\section{Tissue microarray (TMA) construction}

See details of TMA construction in Additional file 5 . Where possible, the TMA cores were obtained from the leading edge of the tumour, thought to be where interactions between ligands in the ECM and the cancer cells were more likely to have functional significance [11]. 


\section{Candidate biomarkers}

The candidate molecules selected for this investigation were: IGFBP-5, VN, fibronectin (FN), $\alpha_{\mathrm{v}}$ integrin, $\beta_{1}$ integrin, total-akt/protein kinase B 1 (Total-AKT1), P-AKT (Ser473), extracellular signal-related kinase-1 and extracellular signal-related kinase-2 (ERK1/2), phosphorylatedextracellular signal-related kinase-1 and extracellular signal-related kinase-2 (P-ERK1/2) (Thr202/Thr204), SHARP-2 and SFN. Oestrogen receptor (ER), progesterone receptor $(\mathrm{PR})$ and HER2 were also selected for investigation.

\section{Immunohistochemistry (IHC)}

The candidate markers were detected using commercially documented antibodies based upon prior independent validation for immunohistological applications in FFPE sections. Refer to Additional file 6 and Additional file 7 for specific details on the antibodies and IHC optimisation protocols, respectively.

\section{Distiller: a secure, web based, flexible information management system}

The virtual TMA slide files created using the NanoZoomer 2.0 series (Hamamatsu ${ }^{\oplus}$, Hamamatsu City, Shizuoka Pref., Japan) digital slide scanner and scanning software NDP.scan 2.0 series (Hamamatsu ${ }^{\odot}$ ) were uploaded into Distiller (SlidePath Ltd Digital Pathology Solutions, Santry, Dublin, Ireland) for image analysis. Distiller was used to facilitate the integration of clinical records, research data, digital TMA slides and different data types into a hierarchical database (see Additional file 8 for information).

\section{Scoring immunohistochemical immunoreactivity}

The digital TMA images were examined and scored by trained anatomical pathology (AP) registrars without prior knowledge of the patient's clinical data (i.e. 'blind') within the Distiller framework. If there were no pathologists available to score the TMAs, they were scored by Helen $C$ Plant. Qualitative differences in the immunoreactivity of the proteins within the cytoplasm, nucleus and membrane of the cells were determined for each TMA core containing either normal breast epithelial ducts (normal), primary breast carcinoma (primary) or metastatic breast carcinoma (LN met). Qualitative differences in staining of the stromal cells and ECM adjacent to normal, primary and LN met tissue were also recorded. Protein immunoreactivity was evaluated semiquantitatively using five scoring methods. These included: presence of protein immunoreactivity; intensity of protein immunoreactivity; percentage of cells with protein immunoreactivity; percentage class and quickscore (Q score) scoring method [12]. Details on these scoring methods and data consolidation strategies are listed in Additional file 9.

\section{Statistical data analysis}

PASW Statistics 18 version 18.0.2 (SPSS, IBM Corporation, Chicago, Illinois, USA) was used to evaluate statistical confidence of the data. The choice of test of association for the five scoring methods of protein immunoreactivity depended on the measurement scale of the scoring method. Presence is a binary outcome (present/ absent) hence Pearson's $\chi^{2}$ test of independence was used. For the ordinal scaled intensity, a Kruskal-Wallis test was employed to determine if any of the groups demonstrated differences. No protected rank-based non-parametric test exists for the post-hoc evaluation of pair-wise differences. Instead, the Mann-Whitney $U$ test was used to evaluate between-groups differences with inflation of family-wise type I error being controlled using Bonferroni corrections. Finally, the remaining three measures of protein immunoreactivity, percentage, percentage class and $Q$ score were all treated as quantitative outcomes and one-way Analysis of Variance (ANOVA) followed by Tukey's HSDs for posthoc testing was used to detect differences. As no rankbased non-parametric method exists to test for effect modification (i.e. interactions), interactions were probed by running the (one-way) Kruskal-Wallis tests for each strata of a potential effect modifier. For all tests, a significance level $(\alpha)$ of 0.05 was used, with the exception of where the Mann-Whitney $U$ was used to test for posthoc differences, where $\alpha_{F W}=\alpha / k=0.05 / 6=0.008$ was used ( $k=6$ represents the number of pairwise comparisons).

\section{Results}

The capability of the ECM and IGF system proteins to regulate cell function, and consequently tumorigenesis, is highly influenced by their spatial arrangement within and around the cell. It was observed that proteins required for IGF- and ECM-induced signalling events are differentially expressed between subcellular and extracellular localisations and that the interpretation of the protein immunoreactivity data is influenced by the scoring method applied. The results described below will only refer to the results obtained for the $Q$ score scoring method [12]. The $Q$ score values $(x)$, including the standard deviation $(S D)$ and sample numbers $(n)$ for each protein across the tissue types and cellular localisation are outlined in Table 1.

\section{Changes in ECM proteins}

The most obvious differences in the immunoreactive distribution between normal breast, primary and metastatic cancer tissue samples was observed in proteins located in the extracellular space surrounding normal breast ducts and primary and metastatic tumours. These findings are intriguing given that the processes occurring during normal breast development are tightly regulated by the ECM and that the ability of the ECM to provide homeostatic regulation is disrupted during the development and 
Table 1 Q-score values for immunoreactivity of each protein across tissue types and cellular localisation

\begin{tabular}{|c|c|c|c|c|c|}
\hline Protein & Cellular localisation & Type of breast tissue & $x$ & $S D$ & $n$ \\
\hline$a_{v}$ integrin & Stroma & Normal & 1.29 & 1.25 & 7 \\
\hline$a_{v}$ integrin & Stroma & Primary & 0.34 & 0.83 & 32 \\
\hline$a_{v}$ integrin & Stroma & LN Metastasis & 0.16 & 0.69 & 19 \\
\hline VN & Cytoplasm & Normal & 0.78 & 1.65 & 23 \\
\hline VN & Cytoplasm & Primary & 2.21 & 2.69 & 86 \\
\hline VN & Cytoplasm & LN Metastasis & 2.44 & 2.38 & 68 \\
\hline VN & Stroma & Normal & 7.13 & 3.75 & 23 \\
\hline VN & Stroma & Primary & 2.84 & 2.73 & 86 \\
\hline VN & Stroma & LN Metastasis & 0.84 & 2.13 & 68 \\
\hline IGFBP-5 & Stroma & Normal & 13.00 & 4.52 & 6 \\
\hline IGFBP-5 & Stroma & Primary & 8.49 & 4.18 & 35 \\
\hline IGFBP-5 & Stroma & LN Metastasis & 4.17 & 4.57 & 23 \\
\hline$\beta_{1}$ integrin & Stroma & Normal & 4.79 & 3.62 & 14 \\
\hline$\beta_{1}$ integrin & Stroma & Primary & 9.71 & 4.36 & 84 \\
\hline$\beta_{1}$ integrin & Stroma & LN Metastasis & 14.47 & 4.21 & 68 \\
\hline FN & Stroma & Normal & 4.08 & 1.88 & 12 \\
\hline FN & Stroma & Primary & 8.66 & 4.42 & 85 \\
\hline FN & Stroma & LN Metastasis & 7.36 & 5.05 & 67 \\
\hline SFN & Nucleus & Normal & 1.07 & 1.73 & 14 \\
\hline SFN & Nucleus & Primary & 3.40 & 3.27 & 82 \\
\hline SFN & Nucleus & LN Metastasis & 3.88 & 2.84 & 68 \\
\hline SFN & Cytoplasm & Normal & 2.93 & 2.30 & 14 \\
\hline SFN & Cytoplasm & Primary & 5.43 & 2.20 & 82 \\
\hline SFN & Cytoplasm & LN Metastasis & 5.75 & 1.93 & 68 \\
\hline SFN & Stroma & Normal & 0.00 & 0.00 & 14 \\
\hline SFN & Stroma & Primary & 0.78 & 0.89 & 82 \\
\hline SFN & Stroma & LN Metastasis & 1.12 & 0.95 & 68 \\
\hline SHARP-2 & Nucleus & Normal & 8.29 & 3.71 & 14 \\
\hline SHARP-2 & Nucleus & Primary & 5.76 & 5.61 & 86 \\
\hline SHARP-2 & Nucleus & LN Metastasis & 3.33 & 3.69 & 70 \\
\hline SHARP-2 & Cytoplasm & Normal & 6.36 & 4.50 & 14 \\
\hline SHARP-2 & Cytoplasm & Primary & 7.90 & 3.72 & 86 \\
\hline SHARP-2 & Cytoplasm & LN Metastasis & 8.80 & 4.57 & 70 \\
\hline T-AKT1 & Nucleus & Normal & 5.69 & 6.91 & 13 \\
\hline T-AKT1 & Nucleus & Primary & 3.39 & 4.08 & 85 \\
\hline T-AKT1 & Nucleus & LN Metastasis & 2.59 & 2.93 & 68 \\
\hline T-AKT1 & Cytoplasm & Normal & 7.54 & 3.76 & 13 \\
\hline T-AKT1 & Cytoplasm & Primary & 8.78 & 3.95 & 85 \\
\hline T-AKT1 & Cytoplasm & LN Metastasis & 9.37 & 3.67 & 68 \\
\hline P-AKT & Nucleus & Normal & 13.50 & 6.21 & 16 \\
\hline P-AKT & Nucleus & Primary & 11.51 & 5.52 & 86 \\
\hline P-AKT & Nucleus & LN Metastasis & 9.32 & 5.44 & 68 \\
\hline P-AKT & Cytoplasm & Normal & 1.19 & 1.47 & 16 \\
\hline P-AKT & Cytoplasm & Primary & 2.19 & 2.12 & 86 \\
\hline
\end{tabular}


Table 1 Q-score values for immunoreactivity of each protein across tissue types and cellular localisation (Continued)

\begin{tabular}{|c|c|c|c|c|c|}
\hline P-AKT & Cytoplasm & LN Metastasis & 2.00 & 2.32 & 68 \\
\hline ERK1/2 & Nucleus & Normal & 2.67 & 2.92 & 15 \\
\hline ERK1/2 & Nucleus & Primary & 1.77 & 2.76 & 84 \\
\hline ERK $1 / 2$ & Nucleus & LN Metastasis & 0.75 & 1.82 & 67 \\
\hline ERK1/2 & Cytoplasm & Normal & 3.73 & 3.31 & 15 \\
\hline ERK1/2 & Cytoplasm & Primary & 6.18 & 4.20 & 84 \\
\hline ERK1/2 & Cytoplasm & LN Metastasis & 5.42 & 3.73 & 67 \\
\hline P-ERK1/2 & Nucleus & Normal & 1.83 & 2.79 & 12 \\
\hline P-ERK1/2 & Nucleus & Primary & 1.89 & 3.47 & 76 \\
\hline P-ERK1/2 & Nucleus & LN Metastasis & 0.41 & 1.03 & 64 \\
\hline P-ERK1/2 & Cytoplasm & Normal & 9.67 & 4.46 & 12 \\
\hline P-ERK1/2 & Cytoplasm & Primary & 10.08 & 4.27 & 76 \\
\hline P-ERK1/2 & Cytoplasm & LN Metastasis & 9.78 & 3.95 & 64 \\
\hline
\end{tabular}

$\mathrm{x}=\mathrm{Q}$ score; $\mathrm{SD}=$ standard deviation; $\mathrm{n}=$ sample size; $\mathrm{LN}=$ lymph node; $\mathrm{P}=$ phosphorylated; $\mathrm{T}=$ Total.

progression of breast cancer. It was observed that the immunoreactivity of key ECM molecules, IGF regulators and integrins decreased with tumour development and/or progression. Significant differences in the immunoreactivity of stromal VN $(p<0.001)$, IGFBP-5 $(p<0.001)$ and $\beta_{1}$ integrin $(p<0.001)$ within the tissue types examined were detected (Figures $1 \mathrm{~A}-\mathrm{C}$ and $2 \mathrm{~A} i$, respectively). Stromal IGFBP-5 and VN immunoreactivity in the metastatic cancer tissues was found to be significantly less than stromal IGFBP-5 and VN immunoreactivity in the normal breast tissues $(p<0.001$ and $p<0.001$, respectively) and primary cancer tissues $(p<0.01$ and $p<0.001$, respectively) (Figure $1 \mathrm{C}$ and $1 \mathrm{~A}$, respectively). Additionally, stromal VN immunoreactivity was greater within normal breast tissue as compared to the immunoreactivity detected in primary cancer tissues $(p<0.001)$ (Figure 1A). Despite not reaching statistical significance $(p=0.054)$, comparable trends were observed for stromal $\alpha_{\mathrm{v}}$ integrin staining with increasing invasiveness of the tissue types examined (Figure 1B).

In contrast, the $\beta_{1}$ integrin immunoreactivity detected in the stroma of metastatic cancer tissue was significantly higher than the $\beta_{1}$ integrin immunoreactivity detected in the stroma in the normal breast $(p<0.001)$ and primary cancer $(p<0.001)$ tissue samples (Figure $2 \mathrm{~A} i$ ). In the primary cancer tissues, stromal reactivity of the $\beta_{1}$ integrin was significantly greater than within the normal breast tissues $(p<0.001)$ (Figure $2 \mathrm{~A} i)$. No statistically significant differences in FN reactivity between the various tissue types were examined $(p=0.094)$ (Figure $2 \mathrm{~B} i$ ). These findings suggest that VN, IGFBP-5 and $\alpha_{\mathrm{v}}$ integrin reactivity in the stroma decreased while stromal $\beta_{1}$ integrin immunoreactivity increased with tumour progression. Figure $2 \mathrm{~B} i$ reveals trends, albeit not statistically significant, which suggest that the stromal localisation of FN differs to that of the other ECM proteins analysed.

\section{Tumour leading edge}

Given these findings, we next investigated whether the distribution of $\beta_{1}$ integrin and $F N$ immunoreactivity within the stroma could be functionally associated with cancer invasion. FN immunoreactivity was observed throughout the stroma immediately adjacent and distal to the leading edges of each tumour (Figure 2Bii $-v$ ). There was also a higher presence of FN immunoreactivity both inside tumour cells at the leading edges and in the stroma directly surrounding the leading edges (Figure $2 \mathrm{~B} i \mathrm{i}-v$ ). In particular, greater membrane and cytoplasmic FN was associated with tumour cells at the leading edge and in close proximity to the leading edge, in contrast to the cells within the middle of the tumour. Paralleling the distribution of FN, $\beta_{1}$ integrin immunoreactivity was detected throughout the stroma immediately surrounding and distant to the leading edges of the tumours (Figure 2Aii - ix). There were many instances where the $\beta_{1}$ integrin was also detected both inside tumour cells at the leading edges and within the stroma of the leading edges of tumours (Figure 2Aii - ix). Again, greater membrane $\beta_{1}$ integrin immunoreactivity was observed in tumour cells at the leading edge and in close proximity to the leading edge, compared to the main bulk of the tumour. However, there were no obvious differences between the cytoplasmic expression of $\beta_{1}$ integrin in cells at the leading edge of tumours and those in the centre of the tumours.

\section{SFN in stroma}

Significant differences were evident in the immunoreactivity of SFN in the stroma of the tissue types examined $(p<0.001)$ (Figure 3). In particular, SFN immunoreactivity scores within the stroma of normal breast tissue were significantly lower than the SFN immunoreactivity scores within stroma of primary $(p<0.05)$ and metastatic 

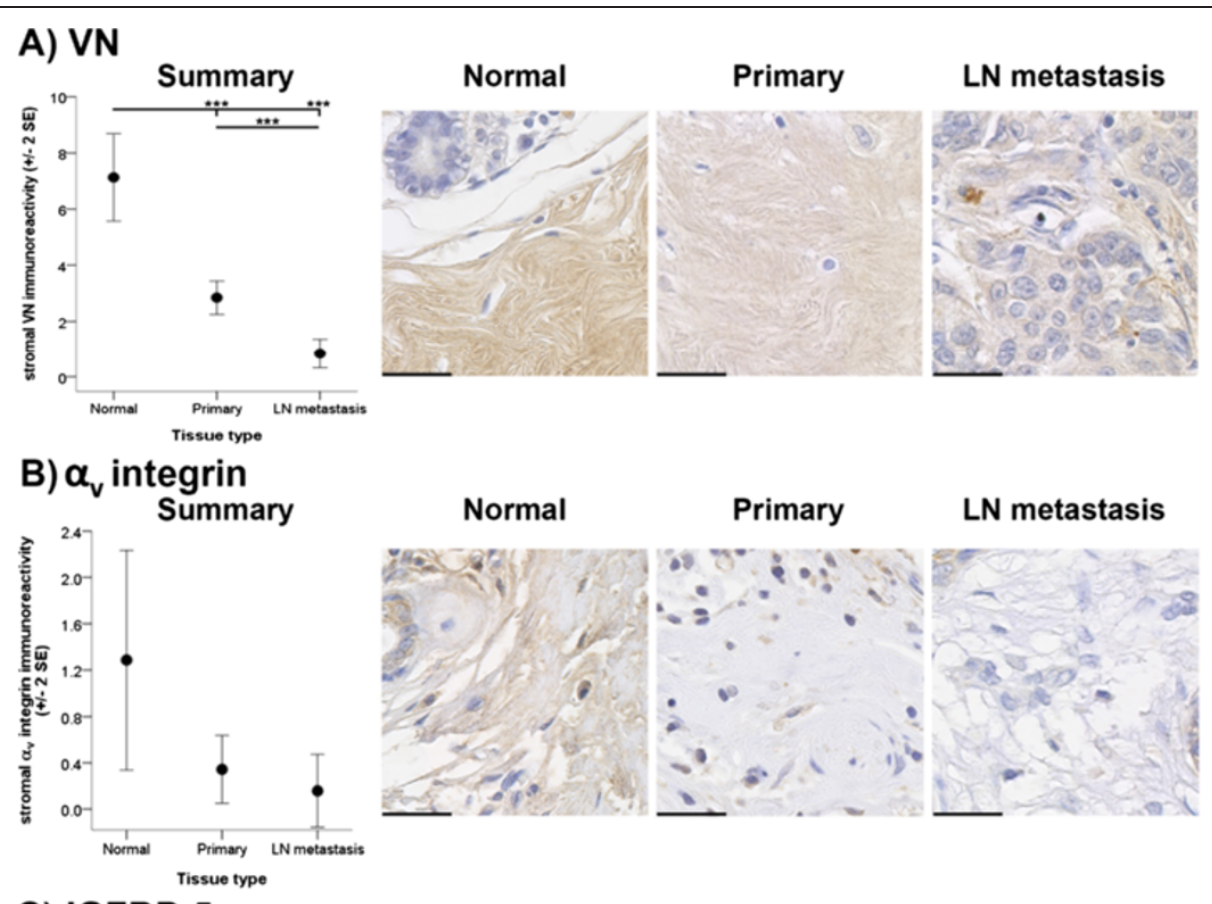

LN metastasis
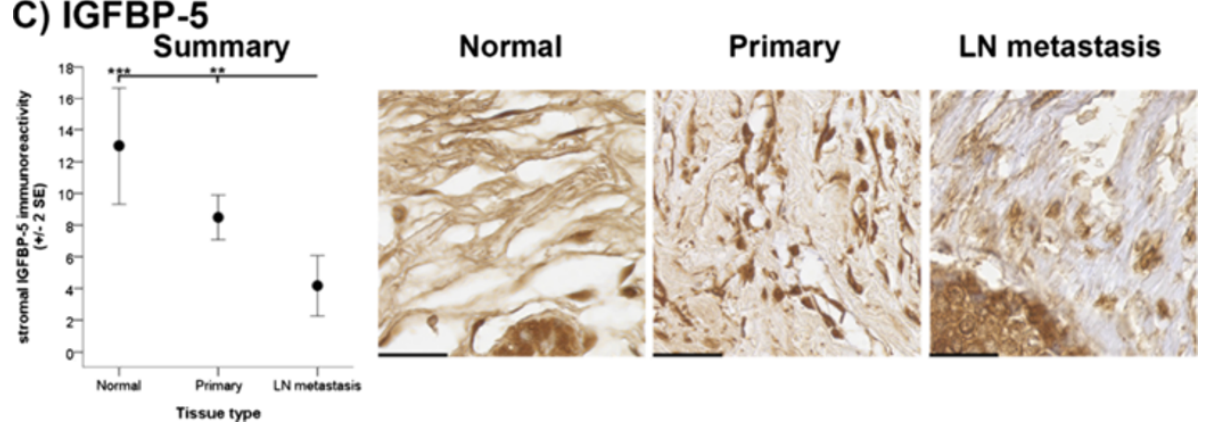

Figure 1 Stromal immunoreactivity of VN, $\boldsymbol{a}_{\mathbf{v}}$ integrin and IGFBP-5. Immunoreactivity of VN (A), $a_{v}$ integrin (B) and IGFBP-5 (C) within the stroma surrounding normal breast (Normal), primary cancer (Primary) and LN metastasis tissues is depicted. Immunoreactivity was evaluated semiquantitatively using the $Q$ score (intensity x percentage class, score: 0 - 18) method. Intensity of reactivity (score: $0=$ negative; $1=$ weak; $2=$ moderate, and; $3=$ strong). Percentage class (score: $1=0-4 \% ; 2=5-19 \% ; 3=20-39 \% ; 4=40-59 \% ; 5=60-79 \% ; 6=80-100 \%$ ). Data are displayed using the mean \pm 2 standard error (SE). Asterisks $\left(* *\right.$ and ${ }^{* * *}$ ) indicate statistically significant differences at $p<0.01$ and $<0.001$, respectively. Scale bar $=30 \mu m$.

cancer tissues $(p<0.001)$. In addition, this finding suggests that SFN immunoreactivity increases in the stroma with tumour development and progression.

\section{Intracellular movement of cell signalling proteins}

The occupation of IGF-IR and integrin molecules results in the recruitment of adapter proteins to the cell membrane and the formation of multiprotein complexes and facilitates the phosphorylation and activation of signalling cascades including AKT and MAPK [13]. The phosphorylation of AKT and MAPK impacts the cellular localisation, specificity and consequently the protein targets of these signalling molecules $[14,15]$. In light of this, the immunoreactivity of Total- and Phosphorylated-AKT and ERK1/2 within the cytoplasm and nucleus of cells from normal breast, primary and metastatic cancers were investigated to determine their role in the downstream signalling events during the development and progression of breast cancer. The intracellular localisation of SHARP-2 and SFN species uniquely regulated by the IGF-I: IGFBP:VN complex [10], were also investigated.

Significant differences in nuclear localisation of P-AKT, ERK $1 / 2$ and SHARP-2 reactivity $(p<0.01, p<0.05$ and $p<$ 0.001 , respectively) were detected between the normal breast, primary cancer and metastatic cancer tissues examined (Figures 4C, D and 5A). More specifically, nuclear P-AKT, ERK1/2 and SHARP-2 immunoreactivity within metastatic cancer tissues was lower than that observed within normal breast tissues $(p<0.05, p<0.05$ and $p<$ 0.01 , respectively) (Figures $4 \mathrm{C}, \mathrm{D}$ and $5 \mathrm{~A}$ ). There was also 


\section{A) $\beta_{1}$ integrin}

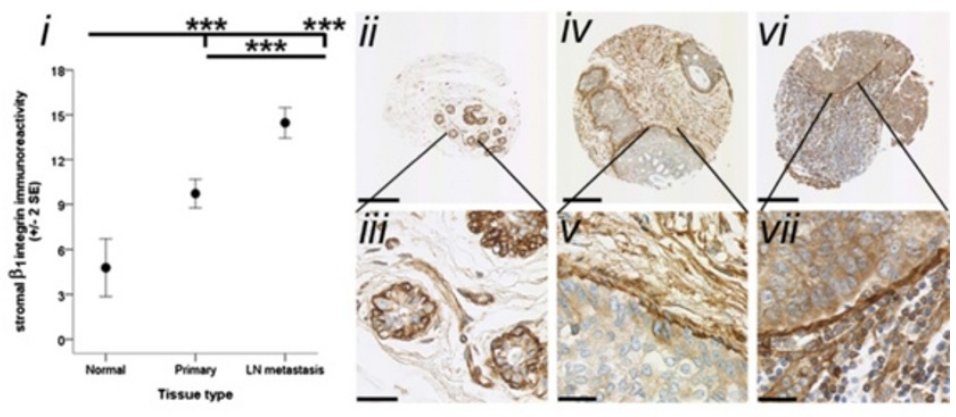

\section{B) FN}
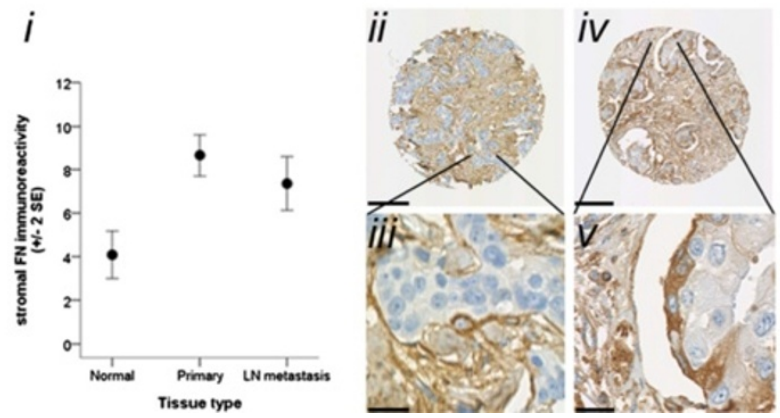

Figure 2 Stromal immunoreactivity of $\beta_{1}$ integrin and FN. Immunoreactivity of $\beta_{1}$ integrin is depicted in $\mathbf{A}$. i) Immunoreactivity of $\beta_{1}$ integrin within the stroma surrounding normal breast (Normal), primary cancer (Primary) and LN metastasis tissues. ii - ix) Representative images demonstrating distribution of $\beta_{1}$ integrin in the stroma and/or cells at the leading edges of Normal (ii and iii), ductal carcinoma in situ (iv and v), Primary (vi and vii) and LN metastasis (viii and ix) tissues. Immunoreactivity of FN is depicted in B. I) Immunoreactivity of FN within the stroma surrounding Normal, Primary and LN metastasis tissues. ii - v) Representative images demonstrating distribution of $\beta_{1}$ integrin immunoreactivity in the stroma and/or cells at the leading edges of Primary (ii and iii) and LN metastasis (iv and $v$ ) tissues. Immunoreactivity was evaluated semiquantitatively using the $Q$ score (intensity x percentage class, score: 0 - 18) method. Intensity of reactivity (score: $0=$ negative; $1=$ weak; $2=$ moderate, and; $3=$ strong). Percentage class (score: $1=0-4 \% ; 2=5-19 \% ; 3=20-39 \% ; 4=40-59 \% ; 5=60-79 \% ; 6=80-100 \%$ ). Data are displayed using the mean \pm 2 standard error (SE). Asterisks (* and ***) indicate statistically significant differences at $p<0.05$ and $<0.001$, respectively. The scale bar for Aii, Aiv, Avi, Aviii, Bii and Biv is $200 \mu \mathrm{m}$ and for Aiii, Av, Avii, Aix, Biii and Bv is $30 \mu \mathrm{m}$.

less nuclear SHARP-2 immunoreactivity within metastatic breast tissue than within primary cancer tissues $(p<0.01)$. Thus, the nuclear localisation of P-AKT, ERK1/2 and SHARP-2 decreased with tumour development and/or progression. In contrast, Figures 4 and 5 reveal trends, albeit not statistically significant, which suggest that the cytoplasmic localisation of Total-AKT1, P-AKT and SHARP-2 may increase with tumour development and/or progression. Additionally, in many of the primary cancer and metastatic (data not shown) tissues in this study there was more nuclear immunoreactivity for SHARP-2 at the periphery of the tumour than was evident in the centre of the tumour (Figure 5B).

We further observed that differences in nuclear and cytoplasmic SFN reactivity $(p<0.05$ and $p<0.001$, respectively) between the normal breast, primary cancer and metastatic cancer tissues were significant (Figure 4A). In particular, nuclear and cytoplasmic SFN within normal breast tissue was lower than the amount of nuclear and cytoplasmic SFN within primary cancer $(p<0.05$ and $p<$ 0.001 , respectively) and metastatic cancer tissues $(p<0.01$ and $p<0.001$, respectively). There were no significant differences in nuclear and cytoplasmic immunoreactivity of SFN between primary and metastatic tumours.

\section{Internalisation of ECM proteins}

Our data also provides evidence that ECM molecules are internalised during breast cancer development and metastasis. Statistically significant differences in cytoplasmic $(p<0.05) \mathrm{VN}$ immunoreactivity was observed between the specific tissue types examined in this study (Figure 6). In particular, lower cytoplasmic $\mathrm{VN}$ immunoreactivity was observed in normal breast tissues than cytoplasmic $\mathrm{VN}$ immunoreactivity within metastatic cancer tissues $(p<0.05)$ (Figure 6). As such, our data indicates that VN redistributes to the cytoplasm with tumour progression. 


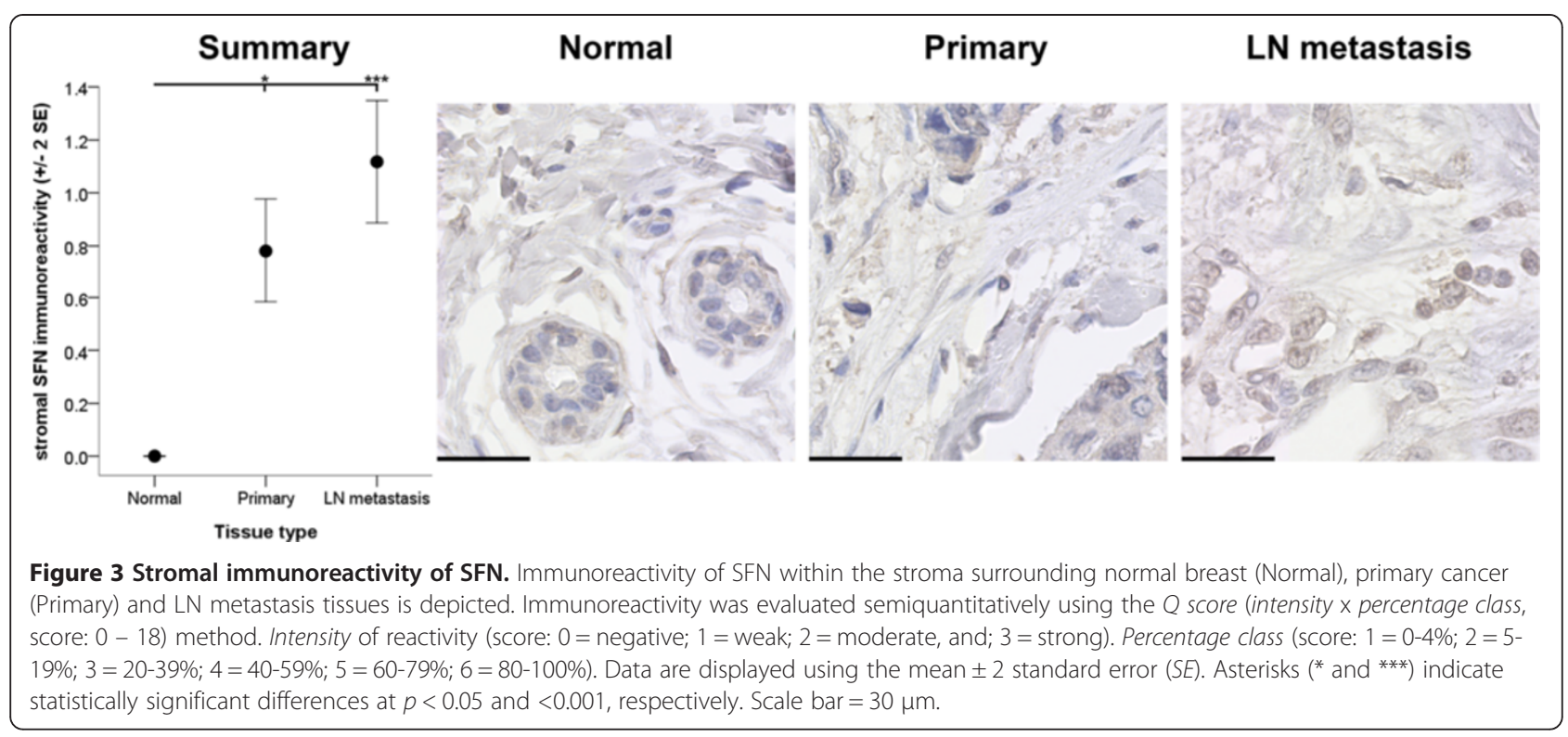

\section{Discussion}

In this study a change in the immunoreactivity of key ECM molecules, IGF regulators and integrins was observed with breast tumour progression. These observations suggest that the ECM surrounding normal breast ductal structures is remodelled during tumour development and progression. The ECM protein FN and the cell surface $\beta_{1}$ integrin (the FN-binding receptor) were found to be highly expressed along the leading edge of many primary tumours in the present study. Interestingly, FN is implicated in epithelial-to-mesenchymal transition (EMT) [16] and both the $\beta_{1}$ integrin and FN are required in the formation of lamellipodia, filopodia and invadopodia [17,18]; potentially supporting their role in ECM remodelling and subsequent tumour cell invasion [19]. Indeed, the $\beta_{1}$ integrin has been reported to be more highly expressed in primary tumours with LN metastases [20] and with poor survival outcomes [21]. This fits in well with our findings that suggest an increase in $\beta_{1}$ integrin immunoreactivity with increasing invasiveness. Various proteases, including matrix metalloproteinases (MMPs) have been implicated in ECM remodelling events that allow cancer cells to migrate [22]. It has been shown that the expression, activity and/or internalisation of MMPs is regulated by integrin-ECM interactions in endothelial cells [23]. Integrins, such as the $\alpha_{\mathrm{v}} \beta_{3}$ integrin, cooperate with MMPs to regulate breast cancer cell migration [24]. Interestingly, IGF-I:VN: IGFBP-5-stimulated breast cell migration, which requires the IGF-IR and VN-binding integrins [9], can regulate the gene expression of proteases such as MMP13, MMP7, ADAMTS5, CPM and protease inhibitors such as SERPINE1 and TRP1 ([10] and supplementary data from [10]).
The data we report here has also provided evidence that ECM molecules and their associated membranebound receptors, the integrins, are internalised during breast cancer development and metastasis. Step-wise increases in cytoplasmic and concomitant decreases in stromal immunoreactivity of $\mathrm{VN}$ and the $\alpha_{\mathrm{v}}$ integrin (data not shown) were evident between normal breast, primary and metastatic cancer tissues. As described previously, $\mathrm{VN}$ can be internalised by integrin receptormediated endocytosis and degraded within the lysosomes [25]. There is also evidence indicating that the VN-binding $\alpha_{\mathrm{v}}$ integrin can be recycled to the cell membrane through intracellular signals [26]. This decrease in the stromal VN and the concomitant increase in the cytoplasmic VN with breast cancer progression suggests a potential re-shuffling or trafficking of $\mathrm{VN}$ from the tumour stroma to the tumour cell cytoplasm with increasing invasiveness of the tumour-type.

Given the importance of the phosphoinositol 3-kinase (PI3K) and mitogen-activated protein kinase (MAPK) signalling pathways in IGF-I: IGFBP:VN-stimulated migration of breast cancer cells in vitro [9], and in IGF-Istimulated ECM re-modelling [27] and EMT events $[27,28]$, protein intermediates within these pathways were also investigated. Decreases in the nuclear immunoreactivity and increases in the cytoplasmic immunoreactivity in breast cancer tissues were observed in this study. We propose a number of explanations for these findings: namely, the preferential activation of substrates in the cytoplasm (of cancer cells) rather than in the nucleus; enzyme-mediated dephosphorylation; and protein internalisation. Both AKT1 and MAPK contain transportation signals which potentially enable their movement throughout a cell $[29,30]$. Defects in these transportation 


\section{Localisation}

ONucleus

A Cytoplasm

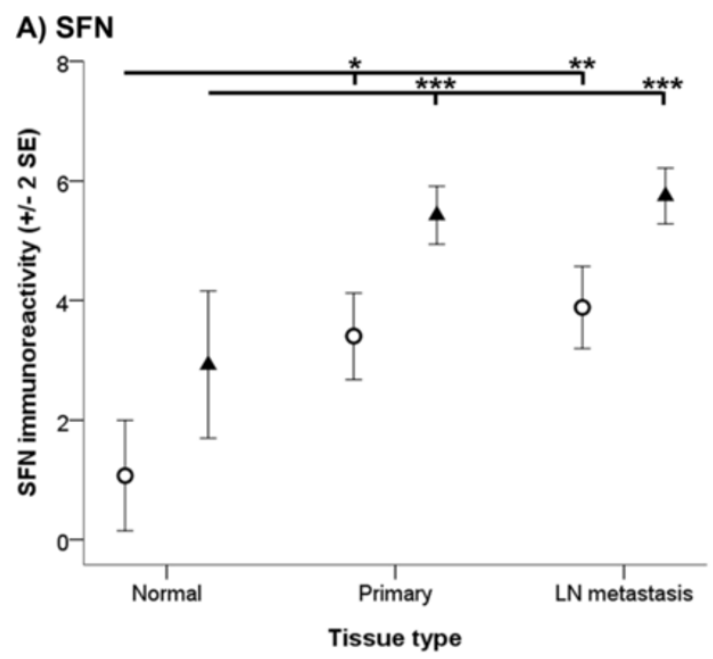

B) Total-AKT1

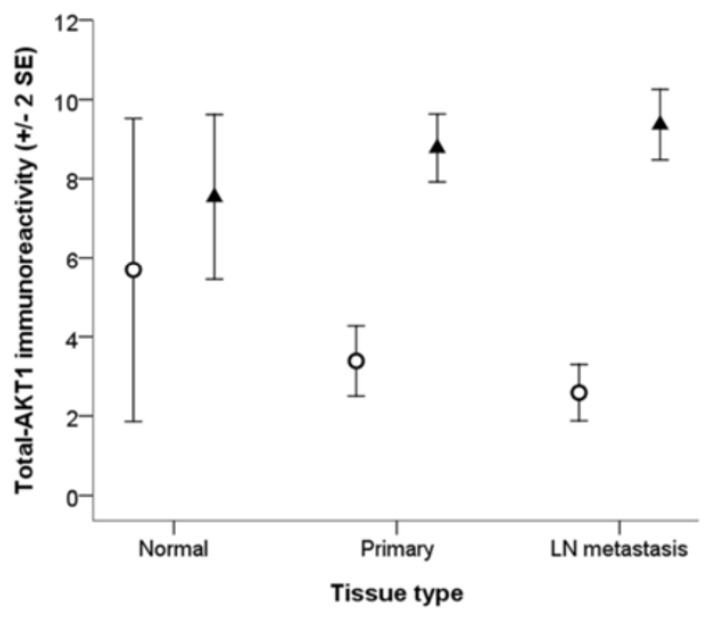

D) ERK 1/2

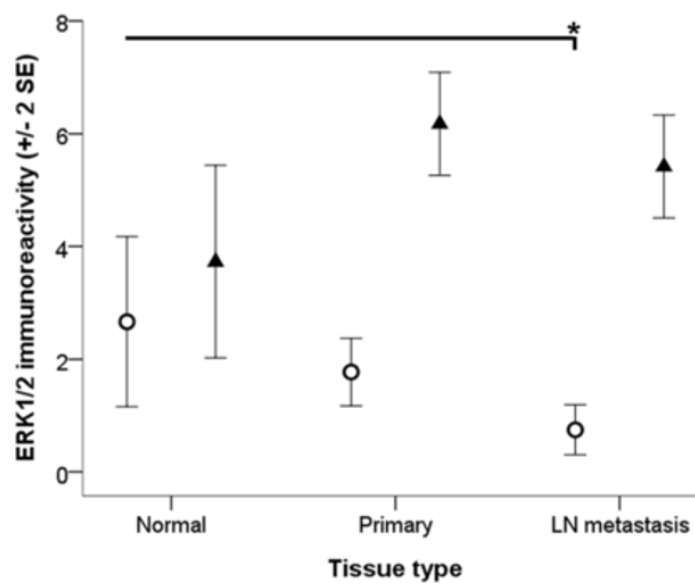

C) P-AKT

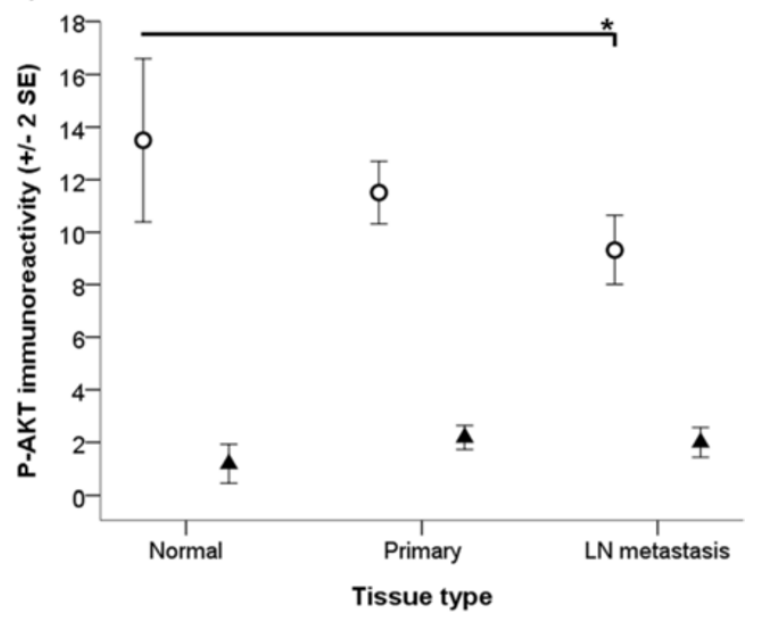

E) P-ERK 1/2

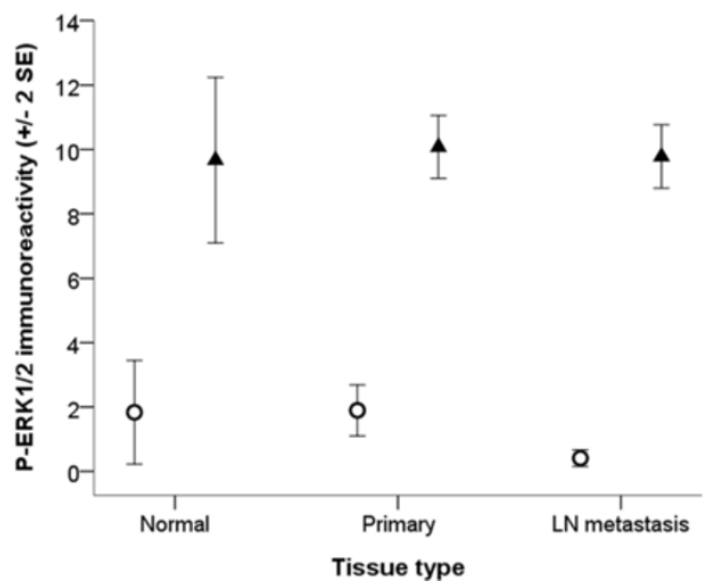


(See figure on previous page.)

Figure 4 Tissue localisation. Differential localisation of SFN (A), Total-AKT1 (B), P-AKT (C), ERK1/2 (D) and P-ERK1/2 (E) is depicted. Nuclear (open circles) and cytoplasmic (closed triangles) immunoreactivity within normal breast (Normal), primary cancer (Primary) and LN metastasis tissues was determined. Antibody immunoreactivity was evaluated semiquantitatively using the Q score (intensity x percentage class, score: 0 - 18) method. Intensity of reactivity (score: $0=$ negative; 1 = weak; 2 = moderate, and; $3=$ strong). Percentage class (score: $1=0-4 \% ; 2=5-19 \% ; 3=20-39 \% ; 4=$ 40-59\%; $5=60-79 \% ; 6=80-100 \%)$. Data are displayed using the mean \pm 2 standard error (SE). Asterisks $\left(*^{* *}\right.$ and $\left.{ }^{* * *}\right)$ indicate statistically significant differences at $p<0.05,<0.01$ and $<0.001$, respectively.

signals during cancer tumorigenesis might explain the results of this study. Ras homolog gene family member $\mathrm{B}$ (RhoB), which has been shown to influence the trafficking of Total- and P-AKT in primary human endothelial cells [31], may impede the import of Total- and $\mathrm{P}-\mathrm{AKT}$ into or promote the export of Total- and P-AKT from the nucleus of breast cancer cells; resulting in an accumulation of AKT in cytoplasmic compartments. Phospho-kinases, such as MAPK, are not necessarily required to enter the nucleus to regulate gene transcription. In fact, the activation of transcription factors in the cytoplasm and their movement into the nucleus for transcriptional control [32] has been reported. The duration and strength of AKT and MAPK signalling in breast epithelial cells can also be regulated in different subcellular locations through the action of various cytoplasmic and nuclear phosphatases [33]. Indeed, phosphatase and tensin homolog (PTEN), a dual lipid and protein phosphatase, can be localised to the cell nucleus [34], and if functional, may therefore de-phosphorylate nuclear AKT. As discussed by Tzivion et al. [35], the ability of a protein to interact with modifying enzymes, such as phosphatases, can be influenced by the presence of 14-3-3 proteins.

Intriguingly, 14-3-3 proteins, including SFN, have been shown to regulate the cytoplasmic sequestration and nuclear retention of cell cycle regulators, many of which are associated with and downstream of the PI3K pathway [36]. It is highly likely that 14-3-3 proteins, such as SFN, may regulate similar sequestration events for P$\mathrm{AKT}$ itself. It was intriguing to find that the increases in the nuclear and cytoplasmic immunoreactivity of SFN with breast cancer development and progression as measured in this study correlated with the increase in mRNA expression of SFN reported by Kashyap et al. [10]. In contrast, other studies have reported the downregulation of SFN expression in breast cancers $[37,38]$. However, Neal et al. [39] showed that overexpression of SFN reduces the overall and disease-free survival of breast cancer patients and is able to predict which patients have a high susceptibility to develop metastasis. Interestingly, it has been proposed that 14-3-3 proteins are important regulators of external environmental signals by eliciting positive and negative effects on the IGF signalling pathway. The ability of 14-3-3 proteins to bind phospho-serine enables them to bind to the IGF-IR [40].
Yang et al. [41] have shown that SFN can also bind to and inhibit the activity of AKT, preventing AKTmediated cellular events. They also indicate that SFN expression was inversely correlated with P-AKT expression [41]; this supports our findings of decreases in nuclear $\mathrm{P}$-AKT and increases in intracellular SFN with tumour development and progression.

We were intrigued to find that SFN was differentially expressed within the stroma surrounding the tissue types examined. Although previous reports of SFN expression have been limited to the cytoplasm of malignant breast cells [38], in vitro evidence indicates that SFN can be excreted by keratinocytes into the pericellular matrix [42]. Extracellular SFN is a key regulator of MMP function and ECM degradation. Studies have shown that following the release of SFN from keratinocytes, MMP-1 mRNA [43] and MMP-1 protein synthesis [44] increases in dermal fibroblasts. Increases in mRNA encoding the $\beta_{1}$ integrin have also been observed in dermal fibroblasts after treatment with SFN, or in co-cultures with keratinocytes known to release SFN [45]. Under the same conditions the expression of many ECM molecules, including collagen type I, FN and $\alpha_{1}$ integrin, decreases. This collective evidence suggests that it is highly likely that SFN may mediate similar functions regulating the degradation of ECM during epithelial tumour development and progression.

We also observed step-wise increases in cytoplasmic and decreases in nuclear immunoreactivity of SHARP-2 between the normal breast, primary and metastatic cancer tissues; this may be explained by nucleocytoplasmic shuttling events. SHARP-2 is known to possess a functional nuclear export sequence (NES) and two nuclear localisation signal (NLS) motifs [46]. A study by Ivanova et al. [46] suggests that SHARP-2 may be required in the nucleus of proliferating and differentiating cells to regulate gene transcription after stimulation by an external factor. They also propose that SHARP-2 may be sequestered in the cytoplasm following cell differentiation.

In summary, we have reported changes in the temporal and spatial distribution of IGF- and ECM-induced signalling proteins that occur during breast cancer metastasis. Specifically, our findings provide further evidence that the ECM surrounding normal breast ductal structures is remodelled during tumour development and progression, and that $\mathrm{FN}$ and the $\beta_{1}$ integrin are 


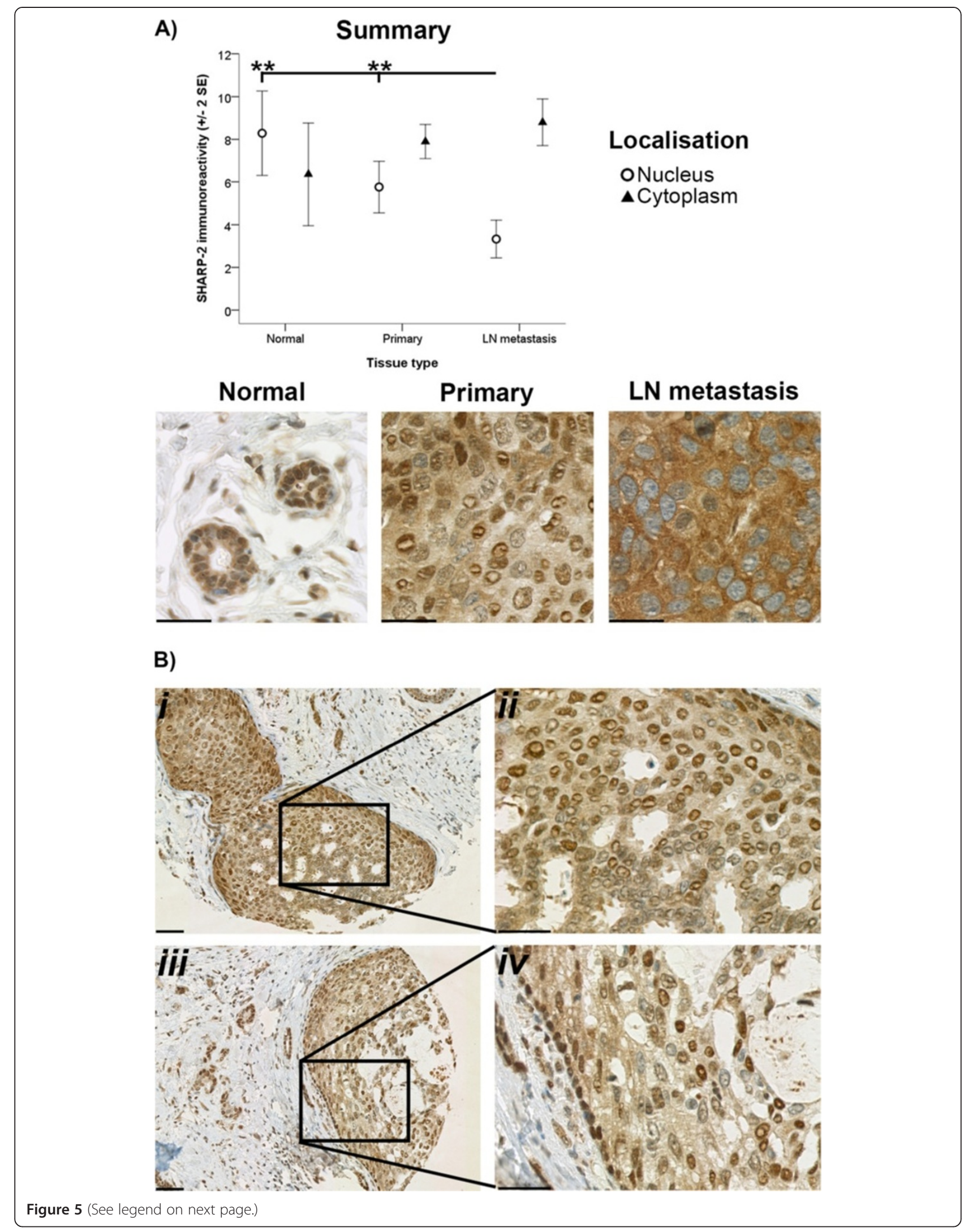


(See figure on previous page.)

Figure 5 SHARP-2 immunoreactivity. Immunoreactivity of SHARP-2 within the nucleus (open circles) and cytoplasm (closed triangles) of cells from normal breast (Normal), primary cancer (Primary) and LN metastasis tissues is depicted in $\mathbf{A}$. Immunoreactivity was evaluated semiquantitatively using the $Q$ score (intensity x percentage class, score: 0 - 18) method. Intensity of reactivity (score: $0=$ negative; $1=$ weak; $2=$ moderate, and; $3=$ strong). Percentage class (score: $1=0-4 \% ; 2=5-19 \% ; 3=20-39 \% ; 4=40-59 \% ; 5=60-79 \% ; 6=80-100 \%$ ). Data are displayed using the mean \pm 2 standard error $(S E)$. Asterisks $(* *)$ indicate statistically significant differences at $p<0.01$. Representative images demonstrating the distribution of SHARP-2 in the cancer cells of primary cancer tissue samples is depicted in $\mathbf{B}(i-i v)$. The scale bar for $\mathbf{A}$, Bii and Biv is $30 \mu \mathrm{m}$ and for Bi and Biii is $200 \mu \mathrm{m}$.

important for the formation of invadopodia and for the epithelial-to-mesenchymal transition events (shown by others [47]) to support dissemination. Analysis of stromal and subcellular SFN immunoreactivity suggested a causal relationship in ECM remodelling events and the localisation and activity of proteins important for IGFand ECM-induced signalling cascades. It also appears plausible that in cells at the leading edge of tumours, SHARP-2 moves into the nucleus to repress the transcription of genes associated with the hypoxic response.

Collectively the above data highlight the possibility that there are broader biological implications of, and explanations for, the differential immunoreactivity of IGF signalling and ECM components in the stroma and/ or in subcellular locations within normal breast, primary breast cancer and metastatic breast cancers. This is highly pertinent given that protein function and protein localisation are closely correlated. Studies have also shown that accounting for protein localisation can be an essential requirement to identifying correlations with other proteins when applying the IHC technique [48]. To date, very few studies have evaluated the prognostic significance of differential protein distribution within diagnostic breast cancer tissue samples. Early studies do,

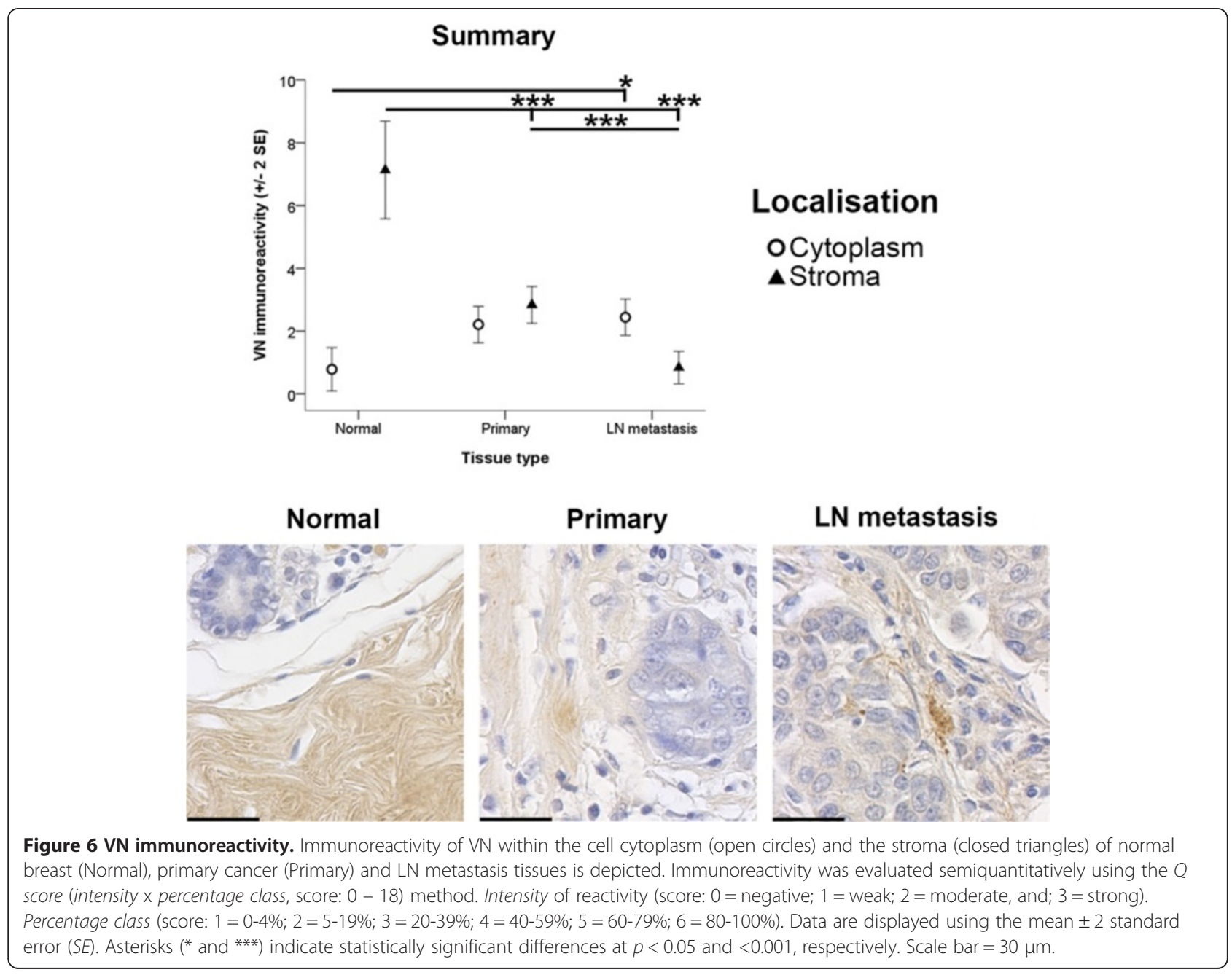


however, suggest that specific locations of specific proteins associated with the IGF signalling cascade and the ECM have shown potential as markers for patient prognosis and therapeutic response [49,50]. We argue that to date the potential of many molecular species to serve as markers of patient prognosis and therapeutic response is being missed by overlooking their subcellular/extracellular distribution. In view of this, we recommend a more complete analysis of protein localisation within diagnostic pathology and improvements to reporting and inclusion of protein localisation in routine pathological examinations as our data indicates the potential role of protein localisation in the progression of disease.

\section{Conclusions}

There is potential that the cellular and ECM events outlined herein could be manipulated to provide clinical benefits and improve the clinical management of breast cancer. In particular, may lead to early prognostic and predictive identification of patients with poor survival outcomes. However, prior to this occurring, the prognostic significance of the cellular and ECM events reported in this study must be identified.

\section{Additional files}

Additional file 1: The actual number of normal breast epithelial duct, ductal carcinoma in situ (DCIS), primary breast carcinoma and/or lymph node (LN) metastasis tissues (n).

Additional file 2: The expected number of normal breast epithelial duct, ductal carcinoma in situ (DCIS), primary breast carcinoma and/or lymph node (LN) metastasis tissues (n).

Additional file 3 The clinico-pathological and survival data for patients.

Additional file 4: The oestrogen receptor (ER), progesterone receptor (PR) and human epidermal growth factor receptor-2 (HER2) status data for patients.

Additional file 5: Working with tissue microarray (TMA). Describes the steps involved in TMA construction, template editing, design computation, punch area selection and heat cycling.

Additional file 6: Product and supplier details for the antibodies used in this study.

Additional file 7: Immunohistochemistry (IHC) conditions for antigen detection.

Additional file 8: Detailed information on steps involved in using the program Distiller.

Additional file 9: Semiquantitative evaluation of immunohistochemical immunoreactivity and consolidation of TMA scoring.

\section{Competing interests}

ZU and DIL provide consultation for Tissue Therapies Ltd. (TIS), an enterprise spun-out from the Queensland University of Technology, Brisbane, to commercialise technology related to the protein interactions described in this manuscript. ZU, DIL and BGH have purchased shares in TIS. GDF has shares in Prognostic Pathology Research Facility and Bioprognostics P/L, private companies with pre-existing IP in development of the database. HCP, ASK, KJM, BGH, CPH, SRS, and GFB have nothing to declare.

\section{Authors' contributions}

HCP carried out the experiments and performed data collection, analysis, and interpretation. ASK was involved in data analysis, drafting and editing of the manuscript and contributed to interpretation of the data. KJM and BGH contributed to the experimental design and interpretation of the data. $\mathrm{CPH}$ designed and performed statistical analyses of the data and contributed to the interpretation of the same. SRS contributed to the experimental design, assisted with data collection and analysis. GDF and GFB sourced the experimental material and contributed to the collection of data, its analysis and interpretation. ZU contributed to the experimental design and interpretation of the data. DIL contributed to the experimental design, the interpretation and analyses of the data and co-ordinated this project. All authors provided editorial assistance and have read and approved this manuscript.

Authors' information

Helen C Plant and Abhishek S Kashyap are co-first authors.

\section{Acknowledgements}

The authors would like to acknowledge Sarah Wagner from the Molecular and Clinical Pathology Research Laboratory (MaCH R), Health Services Support Agency (HSSA), Queensland Health based at the Princess Alexandra Hospital, Brisbane for laboratory assistance. This project was supported by Wesley Research Institute Grants (\#2007-06 and \#2010-04), Australia.

\section{Author details}

${ }^{1}$ Tissue Repair and Regeneration Program, Institute of Health and Biomedical Innovation, Queensland University of Technology, Brisbane, Australia.

${ }^{2}$ Academic Clinical Research Office, Faculty of Medicine, Khon Kaen University, Khon Kaen, Thailand. ${ }^{3}$ Pathology Queensland, Royal Brisbane and Women's Hospital, Brisbane, Australia. ${ }^{4}$ Royal Brisbane and Women's Hospital, Brisbane, Australia.

Received: 19 September 2013 Accepted: 21 August 2014 Published: 29 August 2014

\section{References}

1. Samani AA, Yakar S, LeRoith D, Brodt P: The role of the IGF system in cancer growth and metastasis: overview and recent insights. Endocr Rev 2007, 28(1):20-47

2. Yuen JS, Macaulay VM: Targeting the type 1 insulin-like growth factor receptor as a treatment for cancer. Expert Opin Ther Targets 2008 12(5):589-603.

3. DeVita V, Hellman S, Rosenburg S: Cancer: Principles \& Practice of Oncology. 7th edition. Philadelphia: Lippincott Williams \& Wilkins; 2005.

4. AlHW, National Breast Cancer Centre \& Australasian Association of Cancer Registries: In Breast Cancer Survival by Size and Nodal Status in Australia. Edited by Breast cancer survival by size and nodal status in Australia. Canberra: AlHW; 2007.

5. Howlader N, Noone AM, Krapcho M, Neyman N, Aminou R, Waldron W, Altekruse SF, Kosary CL, Ruhl J, Tatalovich Z, Cho H, Mariotto A, Eisner M, Lewis DR, Chen HS, Feuer EJ, Cronin KA, Edwards B: SEER Cancer Statistics Review, 1975-2008. Bethesda, MD: National Cancer Institute; 2011

6. Paik S, Shak S, Tang G, Kim C, Baker J, Cronin M, Baehner FL, Walker MG Watson D, Park T, Hiller W, Fisher ER, Wickerham DL, Bryant J, Wolmark N: A multigene assay to predict recurrence of tamoxifen-treated, node-negative breast cancer. N Engl J Med 2004, 351(27):2817-2826.

7. Glas AM, Floore A, Delahaye LJ, Witteveen AT, Pover RC, Bakx N, LahtiDomenici JS, Bruinsma TJ, Warmoes MO, Bernards R, Wessels LF, Van't Veer $\mathrm{LJ}$ : Converting a breast cancer microarray signature into a high-throughput diagnostic test. BMC Genomics 2006, 7:278

8. Kricker JA, Towne CL, Firth SM, Herington AC, Upton Z: Structural and functional evidence for the interaction of insulin-like growth factors (IGFs) and IGF binding proteins with vitronectin. Endocrinology 2003, 144(7):2807-2815.

9. Hollier BG, Kricker JA, Van Lonkhuyzen DR, Leavesley DI, Upton Z: Substrate-bound insulin-like growth factor (IGF)-I-IGF binding proteinvitronectin-stimulated breast cell migration is enhanced by coactivation of the phosphatidylinositide 3-Kinase/AKT pathway by alphav-integrins and the IGF-I receptor. Endocrinology 2008, 149(3):1075-1090.

10. Kashyap AS, Hollier BG, Manton KJ, Satyamoorthy K, Leavesley DI, Upton Z: Insulin-like growth factor-l:vitronectin complex-induced changes in gene 
expression effect breast cell survival and migration. Endocrinology 2011, 152(4):1388-1401.

11. Gladson CL, Cheresh DA: Glioblastoma expression of vitronectin and the alpha $v$ beta 3 integrin. Adhesion mechanism for transformed glial cells. J Clin Invest 1991, 88(6):1924-1932.

12. Detre S, Saclani Jotti G, Dowsett M: A "quickscore" method for immunohistochemical semiquantitation: validation for oestrogen receptor in breast carcinomas. J Clin Pathol 1995, 48(9):876-878.

13. Ivaska J, Heino J: Cooperation between integrins and growth factor receptors in signaling and endocytosis. Annu Rev Cell Dev Biol 2011, 27:291-320.

14. Rosner M, Hanneder M, Freilinger A, Hengstschlãxger M: Nuclear/ cytoplasmic localization of Akt activity in the cell cycle. Amino Acids 2007, 32(3):341-345

15. Roux PP, Blenis J: ERK and p38 MAPK-activated protein kinases: a family of protein kinases with diverse biological functions. Microbiol Mol Biol Rev 2004, 68(2):320-344.

16. Zeisberg M, Neilson EG: Biomarkers for epithelial-mesenchymal transitions. J Clin Invest 2009, 119(6):1429-1437.

17. Destaing O, Planus E, Bouvard D, Oddou C, Badowski C, Bossy V, Raducanu A, Fourcade B, Albiges-Rizo C, Block MR: beta1A integrin is a master regulator of invadosome organization and function. Mol Biol Cell 2010, 21(23):4108-4119.

18. Mueller SC, Chen WT: Cellular invasion into matrix beads: localization of beta 1 integrins and fibronectin to the invadopodia. J Cell Sci 1991, 99(Pt 2):213-225

19. Nakahara H, Mueller SC, Nomizu M, Yamada Y, Yeh Y, Chen WT: Activation of beta1 integrin signaling stimulates tyrosine phosphorylation of p190RhoGAP and membrane-protrusive activities at invadopodia. J Biol Chem 1998, 273(1):9-12.

20. Leth-Larsen R, Lund R, Hansen HV, Laenkholm AV, Tarin D, Jensen ON, Ditzel $\mathrm{HJ}$ : Metastasis-related plasma membrane proteins of human breast cancer cells identified by comparative quantitative mass spectrometry. Mol Cell Proteomics 2009, 8(6):1436-1449.

21. Ioachim E, Charchanti A, Briasoulis E, Karavasilis V, Tsanou H, Arvanitis DL, Agnantis NJ, Pavlidis N: Immunohistochemical expression of extracellular matrix components tenascin, fibronectin, collagen type IV and laminin in breast cancer: their prognostic value and role in tumour invasion and progression. Eur J Cancer 2002, 38(18):2362-2370.

22. Kessenbrock K, Plaks V, Werb Z: Matrix metalloproteinases: regulators of the tumor microenvironment. Cell 2010, 141(1):52-67.

23. Galvez BG, Matias-Roman S, Yanez-Mo M, Sanchez-Madrid F, Arroyo AG: ECM regulates MT1-MMP localization with beta1 or alphavbeta3 integrins at distinct cell compartments modulating its internalization and activity on human endothelial cells. J Cell Biol 2002, 159(3):509-521.

24. Rolli M, Fransvea E, Pilch J, Saven A, Felding-Habermann B: Activated integrin alphavbeta3 cooperates with metalloproteinase MMP-9 in regulating migration of metastatic breast cancer cells. Proc Natl Acad SC U S A 2003, 100(16):9482-9487.

25. Panetti TS, McKeown-Longo PJ: The alpha v beta 5 integrin receptor regulates receptor-mediated endocytosis of vitronectin. J Biol Chem 1993, 268(16):11492-11495.

26. Roberts M, Barry S, Woods A, van der Sluijs P, Norman J: PDGF-regulated rab4-dependent recycling of alphavbeta3 integrin from early endosomes is necessary for cell adhesion and spreading. Curr Biol 2001, 11(18):1392-1402.

27. Walsh LA, Damjanovski S: IGF-1 increases invasive potential of MCF 7 breast cancer cells and induces activation of latent TGF-beta1 resulting in epithelial to mesenchymal transition. Cell Commun Signal 2011, 9(1):10

28. Sivakumar R, Koga H, Selvendiran K, Maeyama M, Ueno T, Sata M: Autocrine loop for IGF-I receptor signaling in SLUG-mediated epithelialmesenchymal transition. Int J Oncol 2009, 34(2):329-338

29. Saji M, Vasko V, Kada F, Allbritton EH, Burman KD, Ringel MD: Akt1 contains a functional leucine-rich nuclear export sequence. Biochem Biophys Res Commun 2005, 332(1):167-173.

30. Chuderland D, Konson A, Seger R: Identification and characterization of a general nuclear translocation signal in signaling proteins. Mol Cell 2008, 31(6):850-861

31. Adini I, Rabinovitz I, Sun JF, Prendergast GC, Benjamin LE: RhoB controls Akt trafficking and stage-specific survival of endothelial cells during vascular development. Genes Dev 2003, 17(21):2721-2732.
32. Macfarlane WM, Smith SB, James RF, Clifton AD, Doza YN, Cohen $P$, Docherty $K$ : The $\mathrm{p} 38$ /reactivating kinase mitogen-activated protein kinase cascade mediates the activation of the transcription factor insulin upstream factor 1 and insulin gene transcription by high glucose in pancreatic beta-cells. J Biol Chem 1997, 272(33):20936-20944.

33. Bermudez O, Pages G, Gimond C: The dual-specificity MAP kinase phosphatases: critical roles in development and cancer. Am J Physiol Cell Physiol 2010, 299(2):C189-C202

34. Baker SJ: PTEN enters the nuclear age. Cell 2007, 128(1):25-28.

35. Tzivion G, Gupta VS, Kaplun L, Balan V: 14-3-3 proteins as potential oncogenes. Semin Cancer Biol 2006, 16(3):203-213.

36. Hermeking $H$, Benzinger $A: 14-3-3$ proteins in cell cycle regulation. Semin Cancer Biol 2006, 16(3):183-192.

37. Mirza S, Sharma G, Parshad R, Srivastava A, Gupta SD, Ralhan R: Clinical significance of Stratifin, ERalpha and PR promoter methylation in tumor and serum DNA in Indian breast cancer patients. Clin Biochem 2010, 43(4-5):380-386

38. Simooka H, Oyama T, Sano T, Horiguchi J, Nakajima T: Immunohistochemical analysis of 14-3-3 sigma and related proteins in hyperplastic and neoplastic breast lesions, with particular reference to early carcinogenesis. Pathol Int 2004, 54(8):595-602.

39. Neal CL, Yao J, Yang W, Zhou X, Nguyen NT, Lu J, Danes CG, Guo H, Lan KH, Ensor J, Hittelman W, Hung MC, Yu D: 14-3-3zeta overexpression defines high risk for breast cancer recurrence and promotes cancer cell survival. Cancer Res 2009, 69(8):3425-3432

40. Craparo A, Freund R, Gustafson TA: 14-3-3 (epsilon) interacts with the insulin-like growth factor I receptor and insulin receptor substrate I in a phosphoserine-dependent manner. J Biol Chem 1997, 272(17):11663-11669.

41. Yang H, Wen YY, Zhao R, Lin YL, Fournier K, Yang HY, Qiu Y, Diaz J, Laronga C, Lee MH: DNA damage-induced protein 14-3-3 sigma inhibits protein kinase B/Akt activation and suppresses Akt-activated cancer. Cancer Res 2006, 66(6):3096-3105.

42. Chavez-Munoz C, Morse J, Kilani R, Ghahary A: Primary human keratinocytes externalize stratifin protein via exosomes. J Cell Biochem 2008, 104(6):2165-2173.

43. Ghahary A, Karimi-Busheri F, Marcoux Y, Li Y, Tredget EE, Taghi Kilani R, Li L, Zheng J, Karami A, Keller BO, Weinfeld M: Keratinocyte-releasable stratifin functions as a potent collagenase-stimulating factor in fibroblasts. J Invest Dermatol 2004, 122(5):1188-1197.

44. Lam E, Kilani RT, Li Y, Tredget EE, Ghahary A: Stratifin-induced matrix metalloproteinase-1 in fibroblast is mediated by c-fos and p38 mitogen-activated protein kinase activation. J Invest Dermatol 2005, 125(2):230-238.

45. Ghaffari A, Li Y, Karami A, Ghaffari M, Tredget EE, Ghahary A: Fibroblast extracellular matrix gene expression in response to keratinocytereleasable stratifin. J Cell Biochem 2006, 98(2):383-393.

46. Ivanova A, Liao SY, Lerman MI, Ivanov S, Stanbridge EJ: STRA13 expression and subcellular localisation in normal and tumour tissues: implications for use as a diagnostic and differentiation marker. J Med Genet 2005, 42(7):565-576.

47. Park J, Schwarzbauer JE: Mammary epithelial cell interactions with fibronectin stimulate epithelial-mesenchymal transition. Oncogene 2014, 33(13):1649-1657.

48. Petricevic B, Vrbanec D, Jakic-Razumovic J, Brcic I, Rabic D, Badovinac T, Ozimec E, Bali V: Expression of Toll-like receptor 4 and beta 1 integrin in breast cancer. Med Oncol 2012, 29(2):486-494.

49. Aleksic T, Chitnis MM, Perestenko OV, Gao S, Thomas PH, Turner GD, Protheroe AS, Howarth M, Macaulay VM: Type 1 insulin-like growth factor receptor translocates to the nucleus of human tumor cells. Cancer Res 2010, 70(16):6412-6419.

50. Yamashita H, Takahashi S, Ito Y, Yamashita T, Ando Y, Toyama T, Sugiura H, Yoshimoto N, Kobayashi S, Fujii Y, Iwase H: Predictors of response to exemestane as primary endocrine therapy in estrogen receptor-positive breast cancer. Cancer Sci 2009, 100(11):2028-2033.

\section{doi:10.1186/1471-2407-14-627}

Cite this article as: Plant et al.: Differential subcellular and extracellular localisations of proteins required for insulin-like growth factor- and extracellular matrix-induced signalling events in breast cancer progression. BMC Cancer 2014 14:627. 